\title{
Desenvolvimento e implementação de uma estratégia de informação: o caso de uma empresa portuguesa do setor imobiliário
}

\author{
Sérgio Maravilhas ${ }^{I}$ \\ http://orcid.org/0000-0002-3824-2828 \\ ${ }^{I}$ Universidade de Salvador, Salvador, BA, Brasil. \\ Docente no Programa de Pós-Graduação em Administração.
}

http://dx.doi.org/10.1590/1981-5344/3042

Neste trabalho analisamos uma empresa de mediação imobiliária, procurando situar a sua atividade nas cinco forças competitivas de Porter. Procedemos ao seu enquadramento sintético, histórico e sócio-económico, e à descrição sumária do setor de atividade onde a empresa atua. Descrevemos alguns instrumentos que permitem identificar as necessidades de informação da empresa na atividade desenvolvida, assim como o papel fundamental da informação como fomentadora de vantagens competitivas. Descrevemos a informação como fator de importância estratégica para qualquer organização e como recurso cuja gestão influencia o bom desempenho das organizações. A gestão de informação inserida na estratégia empresarial revela ser um fator chave na obtenção de vantagens competitivas para a organização. Salientamos a importância do envolvimento da gestão ao mais alto nível de forma a possibilitar o efetivo envolvimento de toda a organização. Para desempenhar convenientemente a sua função, o gestor de informação deve ter à sua disposição toda a informação interna relevante, pois só conhecendo de forma aprofundada a organização poderá encontrar as melhores soluções de informação. Para concluir, algumas chamadas de atenção para os elementos a considerar na elaboração da estratégia de informação a implementar.

Palavras-chave: Gestão estratégica da informação, informação interna e externa, information overload, setor imobiliário, sistemas e tecnologias de informação, vantagem competitiva 


\section{Development and implementation of an information strategy: the case of a real estate Portuguese company}

In this paper we analyze a Real Estate company, seeking to locate their activities in Porter's five competitive forces. We proceed with its framing, historical and socioeconomic, and brief description of the activity sector in which the company operates. We describe some tools to identify the information needs of business activity developed, as well as the role of information as a promoter of competitive advantages. We describe the information as a factor of strategic importance for any organization and as a resource whose management influences the performance of organizations. The information management embedded in business strategy proves to be a key factor in achieving competitive advantage for the organization. We emphasize the importance of the involvement of management at the highest level in order to enable the effective involvement of the entire organization. To carry out effectively its function, the information manager must have at its disposal all the relevant internal information because only by knowing in depth the organization can find the best information solutions. To conclude, a few reminders to the factors to consider in developing the information strategy to implement.

Keywords: Strategic information management, internal and external information, competitive advantage, information systems and technologies, information overload, real estate

Recebido em 08.05.2017 Aceito em 30.07.2019

\section{Introdução}

Neste trabalho procuramos analisar de que forma a implementação de uma estratégia de informação é vital para qualquer organização na época histórica em que vivemos, pois viemos de uma sociedade industrial para a era da informação (GLEICK, 2011), onde a exploração eficiente da informação como recurso económico e um setor de produção se tornou um fator de importância estratégica, económica, social e política (BEST, 1996). 
A informação, a par com os recursos naturais e económicos, revelase um recurso social estratégico sem precedentes (MCGEE; PRUSAK, 1995; BEUREN, 1998). Tem, por isso, um valor potencial estratégico quer na identificação de novas oportunidades de mercado, quer na identificação de potenciais ameaças para a empresa (GOMES; BRAGA, 2001; CHOO, 2003), dois aspetos a ter em conta por qualquer empresa que quer atingir os seus objetivos. Por isso, a importância da informação para as organizações é hoje universalmente aceite, constituindo, senão o mais importante, pelo menos um dos recursos cuja gestão mais influencia o sucesso das organizações (WARD; GRIFFITHS, 1996). A informação é também considerada e usada em muitas organizações como um fator estruturante e um instrumento de gestão da organização (ZORRINHO, 1991), assim como uma arma estratégica indispensável para obter vantagens competitivas (PORTER, 1985). A essa informação, indispensável para o funcionamento pleno da organização, dá-se o nome de informação estratégica (EARL, 1998; HINTON, 2006), uma vez que serve para suster a posição competitiva da organização. Aos sistemas que identificam, armazenam, organizam e disponibilizam essa informação, dáse o nome de sistemas estratégicos de informação (DAVENPORT; MARCHAND; DICKSON, 2004).

Analisaremos a situação de uma empresa do ramo imobiliário, a $V$ $A^{1}$, procurando situar o seu setor de atividade nas cinco forças de Porter (1980). Tentaremos mostrar algumas vantagens de intentar uma estratégia de informação devidamente delineada, com a intervenção de todos os colaboradores da organização, deixando a coordenação da mesma ao cuidado de um gestor de informação. Alertaremos para os riscos de deixar tal tarefa ao cuidado do setor de tecnologias de informação (TI) e do perigo de excesso de informação. Concluiremos tentando clarificar alguns destes pontos vincando os benefícios da realização de tal atividade.

Lembramos que nunca é fácil obter informação estratégica confidencial de uma organização por razões competitivas.

Toda a informação da empresa e da atividade aqui descrita foi obtida através de observação participante e de entrevistas pessoais com os três sócios-gerentes, com cinco dos atuais dez diretores de filial e com o responsável do departamento de sistemas de informação e seus dois colaboradores.

A informação aqui revelada é apenas aquela que nos foi autorizada divulgar, dada a necessidade de manter certas informações confidenciais fora do alcance da concorrência, extremamente agressiva neste setor na atual conjuntura económica, e de manter a imagem e reputação da empresa perante os seus clientes, parceiros e colaboradores.

\footnotetext{
${ }^{1}$ Por motivos deontológicos não será referido o nome completo da empresa, mas apenas uma sigla quando nos referirmos à mesma no decurso deste trabalho.
} 


\section{A gestão estratégica da informação}

Uma estratégia de informação define as necessidades de informação da organização, assegurando que os serviços de informação existentes para satisfazer essas necessidades são apropriadamente organizados e geridos, e recorre às TI para o armazenamento, pesquisa, distribuição, comunicação e segurança da informação (WILSON, 1987; 1989b; 1994b).

De salientar o papel preponderante da gestão de informação e a sua inserção na estratégia empresarial, que se revela um fator chave na criação de valor acrescentado para a empresa, pois ajuda a detetar novas oportunidades e a criar vantagens competitivas e possibilita defendê-la de ameaças provenientes da concorrência. A gestão de informação é, então, uma atividade que visa regular a informação, as TI e seus respetivos utilizadores, mediante a aplicação de técnicas de gestão, para processar e disponibilizar informação atualizada e pertinente, através de meios eletrónicos ou não, em função das necessidades dos utilizadores.

A organização deve começar o seu planejamento estratégico através da elaboração de um perfil de indústria. Este é uma função de gestão essencial, porque permite uma avaliação mais eficaz da situação da empresa no setor onde se insere ou dos setores de que a empresa depende para sobreviver e envolve: i) Conhecimento do meio onde a empresa opera (fatores STEEP) ${ }^{2}$; ii) Estatísticas e previsões para a indústria partindo do estado atual do setor e dos setores relacionados; iii) Identificação e análise das maiores empresas do setor, suas principais concorrentes, e práticas desenvolvidas pelas mesmas.

Este perfil permitirá construir um mapa coerente da situação da empresa no seu setor e as situações com que terá de lidar que deverão ser incluídas na estratégia.

\section{A empresa de mediação imobiliária $\boldsymbol{V}$ A: síntese de enquadramento histórico e sócio - económico}

A $V A$ é a segunda maior empresa de mediação imobiliária da zona Norte de Portugal e foi uma das maiores do país, tanto em número de departamentos, lojas e colaboradores, como em volume de vendas e resultados líquidos. Com mais de trinta anos de existência, sediada no Porto onde se localizam os escritórios centrais bem como a maioria das suas atuais dez lojas, possuía em 2001 cerca de cinquenta lojas, que se distribuíam desde Valença do Minho até Leiria e registou no ano de 1999 um volume de negócios na ordem dos 100 milhões de Euros ${ }^{3}$.

Esse valor tem baixado anualmente, fruto da conjuntura que o país atravessa, sendo atualmente quase insuficiente para fazer face às despesas de manutenção da empresa. É constituída principalmente por

\footnotetext{
2 STEEP - Sociological, Technological, Environmental, Economic and Political factors. Em português utiliza-se o acrónimo PEST ou PESTAL (Políticos, Económicos, Sociológicos, Tecnológicos, Ambientais e Legais) para designar estes fatores.

${ }^{3}$ Não fomos autorizados a disponibilizar informação financeira mais recente, sendo os valores atuais uma pálida lembrança dos valores de faturamento entre 1994 e 1999. Conforme acima referido, atualmente o volume de faturamento é praticamente para cobrir as despesas fixas mensais.
} 
departamentos de vendas e arrendamentos, apoiados por departamentos jurídicos, de seguros, de documentação, de Marketing e publicidade, de informática, administrativos, de contabilidade e também de formação (atualmente desativado em virtude da quebra no volume de negócios e no número de colaboradores a formar). Contou com mais de seiscentos colaboradores, sendo a maioria empresários em nome individual (corretores de imóveis) que desenvolvem a sua atividade na área das vendas, sendo esse número atualmente inferior a cem colaboradores.

Uma vez que a empresa atua num setor extremamente agressivo e altamente competitivo, com uma rotação de produtos para venda e de recursos humanos $(\mathrm{RH})$ das mais elevadas da área do comércio, serviços e afins, é imprescindível para a sua sobrevivência que encare o desenvolvimento e implementação de uma estratégia de informação organizacional de forma a preservar e manter a sua atividade num mercado cada vez mais exigente como é o da mediação imobiliária.

\section{Instrumentos e ferramentas a utilizar na estratégia de informação a desenvolver}

Alguns instrumentos para detetar as necessidades de informação da empresa são os seguintes: i) Análise comparativa do setor a que a organização pertence (Benchmarking); ii) Análise da cadeia de valor e identificação das áreas críticas de atividade da empresa; iii) Análise das cinco forças de Porter (1980, 1985), de forma a compreender de que direção vem a pressão mais importante para a organização; iv) Análise SWOT $^{4}$, para perceber as forças, fraquezas, oportunidades e ameaças a que a empresa está sujeita e deve procurar prevenir e melhorar.

De acordo com Porter (1980), dever-se-á ter em atenção as cinco forças que definem, regulam e mantêm o mercado onde a organização opera e atua, de forma a evitar situações imprevistas que podem fazer perigar a sua integridade económica e profissional.

As implicações das cinco forças a considerar e sua relação com a atividade desenvolvida pela organização são: i) As firmas rivais ou competição direta dentro do setor; ii) Os fornecedores; iii) Os clientes; iv) Os serviços ou produtos substitutos; v) Os potenciais novos concorrentes que podem vir a entrar no setor de atividade da organização.

Esta última ameaça é sem dúvida uma das mais prementes e incómodas, devido à falta de regularização e legislação eficazes do setor. Nesta conjuntura, a informação ${ }^{5}$ desempenha um papel fundamental, uma vez que esta afeta a competição a três níveis: i) modifica a estrutura industrial e, assim sendo, altera as regras da competição; ii) cria vantagem competitiva oferecendo às empresas novas formas de ultrapassar as suas rivais; iii) cria novas oportunidades de negócio, a

\footnotetext{
${ }^{4}$ SWOT - Strengths, Weaknesses, Opportunities, Threats. Em português utiliza-se o acrónimo FAFO para designar estes fatores.

5 "Informação é um processo que visa o conhecimento, ou, mais simplesmente, informação é tudo o que reduz a incerteza... Um instrumento de compreensão do mundo e da ação sobre ele" (ZORRINHO, 1995, p. 21).
} 
maior parte das vezes a partir dos processos produtivos internos à organização (PORTER, 1985).

\subsection{Análise das cinco forças de Porter relativamente ao setor em que se enquadra a organização}

A mediação imobiliária é, acima de tudo, uma atividade que presta serviços, uma vez que quem vende é o proprietário do imóvel e não a própria empresa. O cerne da atividade é encontrar o imóvel certo que o cliente procura e fazê-lo chegar a acordo com o proprietário, havendo lugar a uma retribuição monetária para a empresa pelo serviço prestado. É o trabalho realizado pelos Agentes que colaboram com a empresa. Assim, relativamente à análise da cadeia de valor de Porter, ou melhor, aos setores críticos da mesma elaborados por Hunsicker (PORTER, 1985; HUNSICKER, 1989; PICOT, 1989), podemos dizer que a $V A$ situa a sua atividade profissional na área das vendas e serviços.

Relativamente às cinco forças podemos referir: i) As firmas rivais ou competição direta dentro do setor - são todas as outras empresas de mediação imobiliária; ii) Os fornecedores - são as pessoas ou entidades que querem vender ou arrendar os seus imóveis; iii) Os clientes - são as pessoas que pretendem comprar ou arrendar um imóvel; iv) Os serviços ou produtos substitutos - são as novas formas de procurar casa através da Internet, em sites bancários ou da concorrência, que fogem aos moldes tradicionais a que a empresa se dedica; $v$ ) Os potenciais novos concorrentes que podem vir a entrar no setor de atividade da organização - são empresas estrangeiras que desenvolvem negócios de franchising no nosso país, antigos colaboradores das empresas mais sólidas que se lançam por conta própria no mercado, os bancos que tentam vender os seus imóveis com crédito malparado, os próprios construtores civis que criam as suas próprias empresas de mediação imobiliária a funcionarem paralelamente ao setor da construção civil, entre outros.

Como se pode verificar, são vários os perigos a evitar e várias as situações que se devem conhecer para que a organização possa continuar a ocupar o lugar de destaque que desde sempre ocupou.

Atualmente a empresa dispõe de uma página na Internet que permite pesquisar os imóveis disponíveis para venda ou arrendamento usando vários critérios como a tipologia, a localização, o preço, a finalidade e o estado em que se encontra o imóvel. Simultaneamente, através de uma parceria com uma entidade bancária, permite a realização de uma simulação do valor a pagar de crédito imobiliário, com aprovação on-line.

Esta estratégia permite diminuir os custos com instalações físicas e com pessoal, sendo um primeiro ponto de contacto para os potenciais clientes que assim podem examinar, através de fotos e pequenos vídeos, as várias opções disponíveis com toda a comodidade, podendo depois dirigir-se a uma loja física para obter acompanhamento personalizado e 
efetuar uma visita aos imóveis de seu interesse e formalizar a conclusão do negócio.

\subsection{A importância da informação na elaboração da estratégia}

A importância da informação ${ }^{6}$ destaca-se pela possibilidade de permitir gerir estratégias que se traduzam em vantagens competitivas (PORTER; MILLAR, 1985) de elevada importância, tais como: i) Liderança de preços - não dos preços a cobrar pelos imóveis, mas possivelmente pelas baixas comissões a cobrar pelos serviços prestados; ii) Diferenciação - poder fornecer um produto ou serviço únicos, com tratamento de todos os documentos e trâmites legais necessários à compra ou arrendamento de um imóvel; iii) Focalização - num determinado produto particular, área de mercado ou consumidor específico, que pode envolver uma diferenciação de custos, ou a publicitação e serviços diferenciados.

Mas, para isso é necessário obter informação estratégica relevante, como por exemplo: 1) Poderá a adaptação às necessidades do consumidor ser melhorada? 2) Poderá a tenacidade da força de vendas e sua localização ser melhorada? 3) Poderá a atenção do consumidor para com produtos comercializados pela empresa ser melhorada? 4) Poderá uma alteração de preços melhorar a quota de mercado da empresa? 5) A utilização das novas TI (Smartphone e Tablet Apps) e redes sociais (Facebook, Twitter, Instagram, Tumblr, Flickr, Google+, Hi5, entre outras) poderá traduzir-se numa maior procura e fidelização pelos consumidores?

São estas as questões a que a empresa deve dedicar especial atenção, e é a este tipo de situação que uma estratégia de informação bem definida será capaz de dar resposta, possibilitando à empresa manter a sua quota de mercado e, se possível, eventualmente vir a melhorá-la (WILSON, 1987; 1989b; 1994b).

\subsection{Especificações da estratégia de informação a implementar}

A gestão de informação deve assentar no desenvolvimento de uma estratégia que envolva toda a organização, tendo principalmente em atenção: i) Os utilizadores; ii) Os recursos de informação; iii) A tecnologia apropriada disponível (WILSON, 1985, p. 65).

Segundo Wilson (1985), um certo número de questões deve ser colocado ao procedermos ao desenvolvimento de uma estratégia, tais como: 1) De que tipo de informação precisam as pessoas para os ajudar a desempenhar as suas tarefas? 2) É-Ihes disponibilizada essa informação? Se sim, com que custo? Se não, com que prejuízo? 3) Que prioridades existem para dirigir quem deve obter que informação? 4) Que métodos de

\footnotetext{
6 "It is no longer appropriate to consider information as simply a fourth factor in production. Corporate management is nothing else but information work. This means that information has become the prime production factor, and the purpose of information management is to make sure that it is put to good use at both strategic and operational levels" (PICOT, 1989, p. 238).
} 
obtenção ou aquisição, armazenamento, organização e distribuição são usados? E, a que custo? 5) Que alternativas existem para cada um destes processos? Quanto custam? 6) Que sistemas seriam melhores? Qual é o seu preço? 7) Qual é o equilíbrio apropriado entre sistemas manuais e computadorizados?

Conceber uma estratégia com base nestas questões significa que uma nova visão, um novo olhar, deve ser considerado em relação à informação e ao papel que esta desempenha na organização.

As especificações a que a estratégia de informação deve obedecer para ser efetivamente implementada e bem-sucedida são: i) A estratégia a implementar deve ser formalmente documentada; ii) Deve ser iniciada pela Administração de topo da empresa; iii) Deverá ser monitorizada por revisões planeadas; iv) Deve basear a provisão de informação em indicadores chave, bem como em análises detalhadas das necessidades de informação da gestão de topo.

De salientar que, a estratégia de informação a desenvolver e implementar para ser bem-sucedida deve integrar as estratégias de: i) Gestão de informação; ii) Sistemas de informação; iii) Tecnologias de informação (WILSON, 1987; 1989b; 1994b).

Todo o processo acima descrito deve ser formalizado, uma vez que muitos estudos (KALSETH, 1991; O'CONNOR, 1993; EARL, 1998) ${ }^{7}$ apontam para uma maior percentagem de sucesso se a Administração estiver envolvida e empenhada, motivando todos os outros intervenientes no processo. Também, se não existir documentação formal, ninguém saberá qual é a estratégia de informação definida para a poder levar a cabo com eficácia e eficiência. No que respeita à monitorização, se esta não for formalmente desempenhada não se poderão levar em conta as mudanças ambientais proporcionadas pela estratégia definida e controlar o seu efetivo cumprimento. Por último, sem uma efetiva análise das necessidades, não existe nenhuma razão aparente para que a estratégia exista.

Mintzberg (1987) sugere que delinear uma estratégia é mais uma arte ou habilidade do que uma ciência, uma vez que esta envolve negociar várias barreiras. Estas barreiras podem ser contrárias à tentativa de implementar qualquer inovação, tais como atitudes hostis por parte do nível de gestão intermédia, como podem ser relativas à problemática de conseguir contratar os colaboradores apropriados ou mesmo dificuldades em quantificar os benefícios decorrentes da referida implementação.

Chegados a este ponto, é importante referir que é indispensável para o gestor de informação, pessoa que deverá ter a seu cargo a definição da estratégia de informação a implementar, saber quais são os fins da organização, quais os seus objetivos e plano estratégico (WARD; GRIFFITHS, 1996), ou por outras palavras, qual é a estratégia de negócio da empresa, quais as metas da empresa para o próximo ano e que tipo de problemas enfrenta presentemente a organização (CLEVELAND, 1985). Se

\footnotetext{
7 "If an ISS is to be properly related to the business strategy, it is important that the Board should be closely involved" (WILSON, 1989b, p. 248).
} 
este tipo de questões não forem disponibilizadas ao gestor de informação, ser-Ihe-á extremamente difícil planear a obtenção e entrega de serviços de informação relacionados com o planeamento estratégico da empresa ou organização (ORNA, 1999). No entanto, só se poderá tomar consciência de qual é a informação estratégica para a empresa, em face dos assuntos estratégicos para o desempenho eficiente da organização em causa (WILSON, 1994b, p. 266).

\subsection{Erros a evitar na implementação da estratégia de informação}

Para uma organização implementar uma estratégia de informação eficaz, dois erros devem ser evitados. O primeiro, diz respeito ao uso de TI e aos responsáveis por este setor serem responsáveis pela coordenação da estratégia. O segundo, diz respeito à obtenção e disponibilização de informação em excesso, ou a denominada information overload. Ambos podem vir a estar relacionados, 0 que procuraremos mostrar. Analisaremos cada um destes pressupostos, à luz de uma estratégia de informação geral, envolvente e englobante, e não compartimentada ao departamento informático da empresa e à estratégia de TI.

Assim, é usual atribuir a responsabilidade de implementação de uma estratégia de informação ao departamento responsável pelos equipamentos informáticos da empresa, confundindo constantemente gestão de informação ${ }^{8}$, com gestão de sistemas de informação e tecnologias de informação (HINTON, 2006).

Apesar de todos deverem cooperar e trabalhar em conjunto em prol dos benefícios daí decorrentes para a empresa, não se trata de um único assunto a tomar em consideração (MCGEE; PRUSAK, 1995; WARD; GRIFFITHS, 1996), e muitas vezes essa confusão leva a que o investimento aplicado em TI não se torne efetivamente rentável (KING; GROVER; HUFNAGEL, 1989; PREMKUMAR; KING, 1994), precisamente pela falta de coordenação entre os vários setores envolvidos.

Vejamos, apesar de existir um departamento de informática na empresa e do responsável pelas TI ter amplo conhecimento do seu setor, normalmente desconhece os restantes fatores que poderão ter implicações no usufruto válido dessas tecnologias (CATTELA, 1981).

Fatores como o grau de conhecimento dos colaboradores relativamente à utilização de $\mathrm{TI}$, que normalmente é pouco ou nulo, as atividades que envolvem a mediação imobiliária tais como, documentação necessária, impostos a pagar e restantes valores envolvidos no processo de compra e venda de imóveis, conhecimentos de gestão para responder adequadamente aos desafios propostos por uma atividade em constante mudança e com constantes ataques da concorrência exterior são

\footnotetext{
8 "Information Management comprises activities including the acquisition, protection, utilization, accessibility and dissemination of information, and also the promotion and management of thrusts to derive maximum benefit from the resource. It also incorporates the development, management and marketing of an enterprise-wide model, and application of the principles of data management" (WARD; GRIFFITHS, 1996, p. 360).
} 
essenciais para a implementação da estratégia de informação e para o bom desempenho da organização.

Por tal motivo, desconhecendo a atividade 'por dentro', poderá ocorrer que julgando estar a corresponder aos interesses da empresa, disponibilizem informação por via eletrónica que ocupará muitos dos colaboradores com assuntos que não sendo relevantes os farão perder tempo útil para o desempenho da atividade (EDMUNDS; MORRIS, 2000). Pela mesma razão enunciada, poderá também ocorrer que a informação disponibilizada não seja aquela que realmente interessa e faz falta, limitando-se a existir uma concentração de informação não filtrada por alguém conhecedor dos meandros da profissão (GOMES; BRAGA, 2001; CHOO, 2003). Podemos, também, concluir facilmente que a simples compra de equipamentos tecnológicos só por si não levará a qualquer vantagem competitiva (MCGEE; PRUSAK 1995; EARL, 1998; DAVENPORT; MARCHAND; DICKSON, 2004), se não forem devidamente enquadrados num plano mais vasto que permita rentabilizar as suas potencialidades ${ }^{9}$.

Isto conduz-nos a outro problema que deve ser seriamente analisado, e que diz respeito à questão da informação em excesso (information overload). Se, por um lado, uma empresa não pode funcionar sem informação, por outro é importante saber usar esse recurso, de forma a melhorar o seu funcionamento. Uma vez que vivemos numa época de abundância de informação, há que saber distinguir a informação útil, relevante e necessária da excedente (WILSON, 2001). Assim, quanto mais rápida a identificação da informação necessária para a empresa e quanto mais rápido o acesso a essa informação, mais facilmente serão atingidos os seus objetivos. Uma vez que as pessoas, e similarmente as organizações, têm um ponto máximo na capacidade de processamento de informação, existe um ponto de saturação a partir do qual o aumento da informação disponível não corresponde a um aumento da sua utilização mas, pelo contrário, corresponde à sua diminuição. Considera-se informação em excesso, em termos pessoais quando alguém tem a perceção (seja o próprio ou um observador) que a informação associada com as tarefas a desempenhar no local de trabalho é maior do que a que pode ser gerida eficaz e efetivamente (EDMUNDS; MORRIS, 2000; WILSON, 2001). Envolve também a perceção de que esse excesso cria um grau de stress ${ }^{10}$ em que a tentativa de adequação às estratégias definidas se revela ineficaz. Será, então, excesso de informação em termos organizacionais, quando a situação em que a extensão da informação individual percebida está suficientemente dispersa na organização reduzindo, assim, a eficácia da totalidade das operações de gestão. Apesar de não ser um fenómeno novo ou recente, tende a agravar-se com

\footnotetext{
9 "An information policy and an information strategy are going to be key management issues in modern organisations as the installation of information technology gains ground. It would be better to evolve the policy and the strategy before implementing the technology" (WILSON, 1985, p. 66).

10 "The machines we have invented to produce, manipulate and disseminate information generate information much faster than we can process it. It is apparent that an abundance of information, instead of better enabling a person to do their job, threatens to engulf and diminish his or her control over the situation. It is now widely recognised that stress can be experienced from a feeling of lack of control" (EDMUNDS; MORRIS, 2000, p. 18).
} 
o advento das TI e da Internet sendo um fator de risco quer em termos de controlo organizacional, quer em termos de saúde dos colaboradores. 0 impacto deste excesso de informação leva a que se perca demasiado tempo, se atrasem as tomadas de decisão, possibilitando distrações das tarefas principais, provocando stress com consequente tensão, falta de satisfação no emprego, atividade social reduzida, cansaço e, em casos mais graves, doença efetiva (WILSON, 2001).

Para finalizar, deve ser tido em atenção que a empresa não é uma ilha (DAVENPORT, 1997), nem vive fechada sobre si própria, sendo imperioso que se monitorize tudo aquilo que se passa no exterior e que diga respeito ao setor de atividade da empresa, quer a nível económico, como político e social (GOMES; BRAGA, 2001), tanto no plano nacional como internacional, sem incorrer no erro para que se alertou no ponto anterior do eventual excesso de informação irrelevante poder interferir com o desempenho da empresa. Assim, a empresa deve apostar fortemente numa estratégia de informação que lhe permita o conhecimento e a análise da totalidade de assuntos intervenientes na sua atividade, tanto a nível interno como externo.

\section{Conclusão}

Para que uma organização se mantenha lucrativa neste início de século, é indispensável estar devidamente preparada para os desafios que a sociedade baseada na informação acarreta (SHAPIRO; VARIAN, 1999; BROWN; DUGUID, 2000). Para isso, deve tentar desenvolver e implementar uma estratégia de informação, que envolva a estratégia de gestão de informação, a estratégia de sistemas de informação e a estratégia de tecnologias de informação, pois só assim se poderá envolver todos os intervenientes indispensáveis para criar de forma harmoniosa um bom entendimento e compreensão do problema a ultrapassar (VARAJÃO, 1998; AMARAL; VARAJÃO, 2000).

Para que a estratégia se revele eficaz, deve ser devidamente documentada e formalizada como qualquer outra iniciativa da empresa, para que todos os colaboradores possam tomar conhecimento das medidas a adotar, sejam elas quais forem depois de decididas por todos os implicados (ORNA, 1999). Deve também contar com um empenhamento genuíno por parte da gestão de topo para que todos constatem a sua importância e se motivem na sua aplicação (EARL, 1998).

Uma vez que o setor da mediação imobiliária tem sido profundamente afetado por sucessivos fatores externos, tais como a subida das taxas de juro, a entrada de empresas estrangeiras mais experientes no ramo, excesso de profissionais liberais a operarem no setor, excesso de oferta de produtos para consumo, crise acentuada na vida política e económico-social do país, recessão internacional, entre outros fatores que têm sérias repercussões na confiança e poder de compra dos consumidores nacionais, é da máxima importância para a 
empresa desenvolver mecanismos de proteção, que the permitam antecipar certos acontecimentos que possam influenciar o setor e torná-lo menos estável. Isso pode ser possível através do processo atrás descrito de dotar a organização de estruturas que canalizem a informação relevante para utilizar quando necessário.

A implementação de tal estratégia deve ter em consideração os planos de negócio futuros da empresa, a atividade que desenvolve e áreas correlacionadas, o que só se tornará eficaz após uma análise prévia do setor e suas implicações para os planos da empresa (MARCHAND; HORTON JR., 1986). Tal estratégia não deverá em nenhuma circunstância ser deixada à responsabilidade apenas do setor de TI da organização, uma vez que este não dispõe de conhecimento da totalidade de pormenores implicados, apesar de também dever ser consultado no que respeita ao seu setor e às mudanças a serem efetuadas para um desempenho eficiente da organização (WARD; GRIFFITHS, 1996; HINTON, 2006).

Dotada de informação relevante, no momento apropriado, ao menor custo possível, a organização ficará melhor preparada para fazer face às adversidades do setor. No entanto, não deve por tal motivo sobrecarregar o bom funcionamento da empresa com informação em excesso, supérflua e redundante, pois isso só fará com que a breve prazo o que deveria ser uma vantagem competitiva se transforme num pesadelo organizacional, conduzindo a uma situação mais desfavorável do que anteriormente dispunha (EDMUNDS; MORRIS, 2000; WILSON, 2001).

O gestor de informação deve velar para que tal não aconteça, desde que a organização the coloque ao dispor os meios indispensáveis para o bom desempenho das suas funções. Uma estratégia de informação bem delineada é um passo à frente dos seus concorrentes mais diretos, o que pode muito bem permitir evitar certos erros e tomar certas decisões que de outra forma seriam totalmente desconhecidas para o órgão decisor (BEST, 1996). Não nos esqueçamos que a função primordial da informação é tentar eliminar a incerteza (WILSON, 1985).

Por fim, apresentamos algumas recomendações que a empresa deve seguir para atingir satisfatoriamente os seus objetivos: a empresa deve encarar a informação como um recurso tão ou mais importante do que qualquer outro de que necessita para funcionar; a empresa deve pensar em apostar na formação dos seus recursos humanos para que estejam à altura de poder responder de forma positiva às alterações que a implementação de uma tal estratégia pode acarretar em termos de conhecimentos de novas TI e soluções de social networking; a Direção da empresa deve definir o valor da informação para a estratégia empresarial da organização; a organização deve facultar um conhecimento exaustivo dos planos da empresa ao seu gestor de informação, para que este possa intervir positivamente na obtenção de recursos válidos; a simples aquisição de tecnologias de informação não é suficiente para a obtenção das vantagens competitivas que elas podem proporcionar. Deve existir um planeamento mais abrangente, elaborado previamente ao desenvolvimento dos equipamentos tecnológicos; a organização deve 
facultar aos seus colaboradores a informação relevante e necessária para o excelente desempenho da sua função minimizando, sempre que possível, a sobrecarga com informação desnecessária; a empresa deve estar atenta não só à informação interna, gerada no seio da organização, de que necessita para levar a cabo as tarefas empresariais de que se ocupa, mas também à informação externa, proveniente de vários pontos de interesse para o setor, de forma a manter a sua atividade rentável; a empresa deve permitir aos seus clientes o acesso aos seus produtos e serviços através de várias soluções tecnológicas de modo a poder satisfazer vários segmentos de mercado que possam ter interesse e/ou necessidade na área de negócio da empresa.

As limitações deste trabalho devem-se a restrições impostas pela organização visada no que respeita à confidencialidade da sua informação, situação compreensível dada a sensibilidade de que se reveste.

Não nos foi possível avaliar as vantagens da implementação de tal estratégia dada a sua recente e ainda pouco explorada utilização pelo que se sugere em momento ulterior proceder à medição e avaliação do desempenho organizacional e ressalvar os benefícios daí decorrentes.

Seria útil e muito importante proceder à elaboração de um caso de estudo com as vantagens e conclusões, erros a evitar e resultados obtidos que permitisse a outras organizações da mesma área de atividade ou de áreas complementares beneficiarem desta experiência, podendo elas próprias implementarem as suas próprias estratégias de informação de forma mais célere e coerente, evitando erros e adaptando soluções mais eficazes para o seu desempenho e permanência no mercado.

\section{Referências}

ADEOTI-ADEKEYE, W. The importance of management information systems. Library Review, v. 46, n. 5, p.318-327, 1997.

AMARAL, L. ; VARAJÃO, J. Planeamento de sistemas de informação. 2. ed. Lisboa: FCA, 2000.

BEST, D. The Fourth resource: information and its management. Chester: Aslib/Gower, 1996.

BEUREN, I. Gerenciamento da informação: um recurso estratégico no processo de gestão empresarial. São Paulo: Atlas, 1998.

BROWN, J. ; DUGUID, P. The social life of information. Boston: Harvard Business School Press, 2000.

CATTELA, R. Information as a corporate asset. Information and Management, v. 4, p.29-37, 1981.

CHOO, C. Gestão de informação para a organização inteligente: a arte de explorar o meio ambiente. Lisboa: Editorial Caminho, 2003.

CLEVELAND, H. A informação como um recurso. In Diálogo. Rio de Janeiro, n. 16, p.7-11, 1983. 
CLEVELAND, $\mathrm{H}$. The knowledge executive: leadership in an information society. New York: Dutton, 1985.

DAVENPORT, T. Information management: a broader approach. Disponível em: http://www.unisys.com/execmag/1997-09/journal/conversation.htm. Acesso em: 12 out 2015.

DAVENPORT, T. Information ecology: mastering the information and knowledge environment. New York: Oxford University Press, 1997.

DAVENPORT, T.; MARCHAND, D. ; DICKSON, T. Dominando a gestão da informação. Porto Alegre: Bookmann, 2004.

DRUCKER, P. As Fronteiras da gestão. Lisboa: Editorial Presença, 1988.

DRUCKER, P. Gerindo para o futuro. Lisboa: Difusão Cultural, 1993a.

DRUCKER, P. Sociedade pós- capitalista. Lisboa: Difusão Cultural, 1993b.

EARL, M. Information management: the organizational dimension. New York: Oxford University Press, 1998.

EDMUNDS, A.; MORRIS, A. The problem of information overload in business organizations: a Review of the Literature. International Journal of Information Management, v. 20, p.17-28, 2000.

GALLIERS, R. Towards a flexible information architecture: integrating business strategies, information systems strategies and business process redesign. Journal of Information Systems, v. 3, p.199-213, 1993.

GLEICK, J. The information: a history, a theory, a flood. St. Ives: 4th Estate, 2011.

GOMES, E.; BRAGA, F. Inteligência competitiva: como transformar informação em um negócio lucrativo. Rio de Janeiro: Campus, 2001.

HINTON, M. Introducing Information Management: the business approach. Burlington: Elsevier Butterworth-Heinemann, 2006.

HUNSICKER, J. Strategies for european survival. The McKinsey Quarterly. Summer, p.37-47, 1989.

INTRONA, L. Management, Information and Power. London: MacMillan, 1997.

JOHANNESSEN, J.; OLAISEN, J. The Information intensive organization.

In: OLAISEN, J. (ed.). Information Management: a scandinavian approach. Oslo: Scandinavian University Press, 1993.

KALSETH, K. Business Information Strategy: The strategic use of Information and Knowledge. Information Services and Use, n. 11, p.155$164,1991$.

KING, W.; GROVER, V.; HUFNAGEL, E. Using information and information technology for sustainable competitive advantage: some empirical evidence. Information and Management, n. 17, p.87-93, 1989. 
MARCHAND, D.; HORTON JR., F. Infotrends: profiting from your information resources: New York, John Wiley \& Sons, 1986.

MARCHAND, D. Infotrends: A 1990s Outlook on Strategic Information Management. Information Management Review, v. 5, n. 4, p.23-32. 1990.

MCGEE, J. V.; PRUSAK, L. Gerenciamento estratégico da informação: aumente a competitividade e a eficiência de sua empresa utilizando a informação como uma ferramenta estratégica. Rio de Janeiro: Campus, 1995.

MINTZBERG, $\mathrm{H}$. The nature of managerial work. New York: Harper and Row, 1973.

MINTZBERG, H. Crafting strategy. Harvard Business Review, July/August, p. 66-75, 1987.

MINTZBERG, H. Rise and fall of strategic planning. New York: Free Press, 1994.

O'CONNOR, A. Successful strategic information systems planning. Journal of Information Systems, n. 3, p. 71-83, 1993.

OLAISEN, J.; REVANG, O. Information management as the main component in the strategy for the 1990s in Scandinavian Airline System (SAS). International Journal of Information Management, n. 11, p. 185202, 1993.

ORNA, E. Practical information policies. 2.ed. Cambridge: Gower, 1999.

PICOT, A. Information Management: The science of solving problems.

International Journal of Information and Management, n. 9, p. 237-243, 1989.

PORTER, M. Competitive strategy: techniques for analyzing industries and competitors. New York: Free Press, 1980.

PORTER, M. Competitive Advantage: creating and sustaining superior performance. New York: Free Press, 1985.

PORTER, M. Competition in global industries. Boston: Harvard Business School Press, 1986.

PORTER, M. A vantagem competitiva dasnNações. Rio de Janeiro:

Campus, 1993.

PORTER, M.; MILLAR, V. How information gives you competitive advantage. Harvard Business Review, p.75-98, . July/Aug. 1985.

POSTMAN, N. Five things we need to know about technological change. Disponível em: http://www.newtech.org/address10 en.htm . Acesso em: 14 out. 2015.

PREMKUMAR, G.; KING, W. The evaluation of strategic information systems planning. Information \& Management, n. 26, p. 327-340, 1994. 
REPONEN, T. Information management strategy: an evolutionary process. Scandinavian Journal of Management, v. 9, n. 3, p. 189-209, 1993.

ROBERTS, N.; CLARKE, D. Organizational information concepts and information management. International Journal of Information Management, n. 9, p.25-34, 1989.

RUE, L.; HOLLAND, P. Strategic management: concepts and experiences. 2. ed. New York: McGraw-Hill, 1989.

SHAPIRO, C. ; VARIAN, H. Information rules: a strategic guide to the network economy. Boston: Harvard Business School Press, 1999.

VARAJÃO, J. A arquitectura da gestão de sistemas de informação. 2. ed. Lisboa: FCA, 1998.

VICKERS, P. Information management: a practical view. Aslib Proceedings, n. 36, p. 245-252, 1984.

WARD, J.; GRIFFITHS, P. Strategic planning for information systems. 2. ed. New York: John Wiley \& Sons, 1996.

WALSHAM, G. Interpreting information systems in organizations.

Chichester: John Wiley \& Sons, 1993.

WILMOT, R. Change in management and the management of change. Long Range Planning, v. 20, n. 6, p. 23-93, 1989.

WILSON, T. Information Management. The Electronic Library, v. 3, n. 1, p. 62-66, 1985.

WILSON, T. Information for business: the business of information. Aslib Proceedings, n. 39, p. 275-279, 1987.

WILSON, T. Towards an information management curriculum. Journal of Information Science, v. 15, n. 4/5,p. 203-209, 1989a.

WILSON, T. The implementation of information system strategies in UK companies: Aims and Barriers to Success. International Journal of Information Management, n. 9, p. 245-258, 1989b.

WILSON, T. Tools for the analysis of business information needs. Aslib Proceedings, v. 46, n. 1, p. 19-23, 1994a.

WILSON, T. The nature of strategic information and its implications for information management. New Worlds in Information and Documentation. Elsevier Science B. V., p. 265-269, 1994 b.

WILSON, T. Information overload: myth, reality and implications for health care. ISHIMR - International Symposium on Health Information Management Research, Halkidiki, Greece, May, 2001.

ZORRINHO, C. Gestão da informação. Lisboa: Editorial Presença, 1991. 